\title{
INDIRECT INDUCTION MOTOR STATOR WINDING TEMPERATURE ESTIMATION
}

\author{
Aleksejs Gedzurs \\ Latvia University of Life Sciences and Technologies, Latvia \\ aleksejs.gedzurs@1lu.lv
}

\begin{abstract}
The paper discusses a novel stator winding temperature estimation method for S1 duty cycle induction motors. The method is based on the rotor speed variation with rotor resistance. Under constant load, rotor resistance changes with temperature, therefore, the rotor speed also changes. There is a linear correlation between the stator and rotor resistance change, thus a correlation between the stator winding temperature and the rotor speed. Experimental tests are performed on three phase $1.1 \mathrm{~kW}$ induction motor under normal and impaired cooling conditions. Statistical analyses show linear correlation between the rotor speed and stator winding temperature. Using rotor speed measurements, stator winding temperature is simulated in MATLABSIMULINK. Simulation results show that there is significant difference between simulation and experimental data during the start of transient period. This is caused by different stator and rotor thermal masses. To overcome this, a combined model of the motor thermal model and rotor speed is presented. The thermal model is used to simulate the stator winding temperature during the start of transient period. Simulation results of the combined model demonstrate adequacy of the presented method to the experimental data. Analyses show that the difference between simulated and experimental results is $2{ }^{\circ} \mathrm{C}$. Therefore, the presented method can be used in protection devices to protect induction motors, especially under impaired cooling conditions and/or high ambient temperature.
\end{abstract}

Keywords: induction motor, stator winding, temperature estimation, speed.

\section{Introduction}

Electric motors account for more than $40 \%$ of total electricity consumption in the world and around $70 \%$ in the EU [1]. Among all electric motors, induction motors (IM) are widely used. A failure of an induction motor can result in stoppage of the production process, therefore causing economical losses. A survey of the reliability of induction motors in the petroleum and chemical industry is presented in [2] and the root cause analysis for IM [3] shows that failures are caused by the following failed components and causes: bearings - in $51 \%$ of the failure cases; stator windings $16 \%$; external (environment, load and voltage) $-16 \%$; others $-17 \%$. In agriculture facilities, $70 \%$ of failures occur due to failed stator windings; $20 \%$ - due to environment or voltage effects; $10 \%$ bearing damages $[4 ; 5]$. Average annual failure rate of motors is $3.4 \%$ and in places of extreme operation conditions it is $9.3 \%$ and can reach up to $12 \%$ [6]. In hen houses 20-30\% of egg production volume depends on microclimate quality [7], therefore, a failure of induction motors driving the fans in the hen houses can lead to a decrease of egg production or even the death of poultry. A survey of induction motor drive systems and failures in the egg processing plant 'Balticovo' in Iecava, Latvia shows that annual induction motor failure was $2.3 \%$ in 2015 [8], but according to new data it is $4.2 \%$ in 2017.The majority of the faulty motors are $1.1 \mathrm{~kW}$ induction motors driving fans in hen houses. The fan induction motors are covered by grain dust and it causes overheating of the IM parts, leading to accelerated failure, especially the stator winding failures. Motor starters do not provide protection against overheating caused by impaired cooling and usage of temperature sensors is not a cost-effective solution for these small $1.1 \mathrm{~kW}$ power induction motors.

There are mainly two approaches to estimate the induction motor temperature - model based and parameter-based approaches. State-of-the-art protection relays use a simple first order thermal model of induction motor [9], but that model is generally too conservative and can disconnect the motor before temperature reaches the thermal limit of the insulation material [10]. The second order thermal model [11] and higher order thermal modelof induction motor provide better temperature estimation accuracy, but require more motor parameter information or performing tests to obtain the thermal parameters of the IM. Input signal of the thermal model is current and voltage measurements, therefore thermal models cannot adapt to impaired cooling conditions and ambient temperature changes. Parameter-based approaches estimate the temperature from the variation of the stator and rotor resistances and can be used to estimate IM temperature under impaired cooling conditions and varying ambient temperature. The resistances can be identified using the following approaches: induction motor model based, neural network and signal injection-based approaches. Induction motor model-based approaches calculate resistances using the IM equivalent circuit [12]. Since the rotor 
resistance is not dependent on the stator resistance, it is calculated first and then the stator resistance. This method is sensitive to errors in calculations and works in the IM steady state operation. The artificial neural network approach to estimate the rotor and stator resistance is used for inverter fed induction motor drive systems [13]. Using an extra circuit connected in series with IM phase [14] or using a soft starter [15] a DC signal is injected and stator resistance calculated. But the injected signal causes small torque pulsations and extra heat losses. In addition, the resistance of the cable from the injection device to the motors needs to be compensated. A combination of the thermal model and parameter-based approach is used in [16]. Measuring currents and voltages with two current and two voltage sensors, the rotor resistance is calculated and then the thermal model's thermal parameters are tuned. This method with two current and two voltage sensors is not a cost-effective option for small power induction motor protection. The aim of this paper is to develop a simplified induction motor stator winding temperature estimation method for S1 duty cycle induction motor.

\section{Materials and methods}

According to [19] the stator resistance is calculated from:

$$
R_{s}=k \cdot R_{r}, k=\frac{R_{s n}}{R_{r n}}
$$

where $R_{s}, R_{r}$ - stator and rotor resistances, $\Omega$;

$R_{s n}, R_{r n}$ - stator and rotor nominal resistances given by manufacturer, $\Omega$.

As it can be seen, there is a correlation between the stator and rotor resistance changes, if the induction motor is loaded. It is known that rotor resistance changes the motor slip and rotor temperature estimation by back calculating from the motor slip is used by motor designers [14]. By increasing rotor resistance, the motor slip increases (rotor speed decreases). In induction motors with a squirrel-cage rotor the rotor resistance change is dependent only on temperature during operation. Stator resistance change is also dependent on the stator winding temperature, therefore, the equation 1 can be modified to:

$$
\Delta \theta_{s}=a \cdot \Delta n, a=\frac{\Delta \theta_{s}}{\Delta n}
$$

where $\theta_{s}$ - stator winding temperature, ${ }^{\circ} \mathrm{C}$;

$n$ - rotor speed, $\min ^{-1}$.

Right after the starting of the induction motor heating of the stator winding is more rapid than rotor winding due to smaller thermal inertia. This is why during this period stator temperature estimation using rotor resistance, or other rotor resistance dependent parameters, will lead to an error. A thermal model then is used to estimate the stator winding temperature during the first few minutes after the motor start. As shown in [20], the first order thermal model causes an error around $5-7^{\circ} \mathrm{C}$ compared to $1.1 \mathrm{~kW}$ IM experimental heating results during the first few minutes of operation. To overcome this, the stator is divided in 2 parts - stator winding and stator frame (with core) and the thermal model equivalent electrical model is shown in Figure 1. Then this model is described by the following equations:

$$
\begin{gathered}
P=\frac{\theta_{s}-\theta_{f}}{R_{1}}+C_{1} \frac{d \theta_{s}}{d t}, \\
\frac{\theta_{s}-\theta_{f}}{R_{1}}=\frac{\theta_{f}}{R_{2}}+C_{2} \frac{d \theta_{f}}{d t},
\end{gathered}
$$

where $\theta_{f}$ - stator frame and core temperature, ${ }^{\circ} \mathrm{C}$;

$\theta_{a}-$ ambient temperature, ${ }^{\circ} \mathrm{C}$;

$C_{1}$ - thermal capacity of stator windings, $\mathrm{J}^{\circ} \mathrm{C}^{-1}$;

$C_{2}$ - thermal capacity of stator frame and core, $\mathrm{J}^{\circ} \mathrm{C}^{-1}$;

$R_{1}$ - thermal resistance between stator winding and core, ${ }^{\circ} \mathrm{C} \cdot \mathrm{W}^{-1}$;

$R_{2}$ - thermal resistance between frame and ambient, ${ }^{\circ} \mathrm{C} \cdot \mathrm{W}^{-1}$; 
$P$ - heat losses, W.

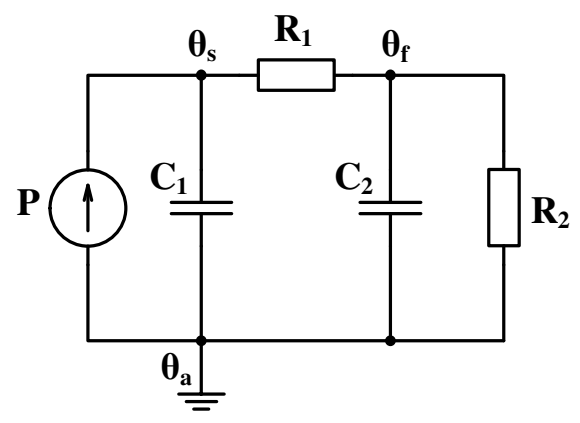

Fig. 1. Thermal model of induction motor

Experimental tests and stator winding temperature simulation are done on a three phase induction motor: ABB M2AA90S-4; 220-240/380-420 V; 4.6/2.66 A; IP55; insulation class - F, $\mathrm{m}=13 \mathrm{~kg}$; $P=1.1 \mathrm{~kW} ; n=1410 \mathrm{~min}^{-1}$; efficiency class $-\mathrm{IE} 1, \cos \varphi=0.81$. Direct current electric generator (P22Y4, 220V , 5.9A, $P=1 \mathrm{~kW}, n=1500 \mathrm{~min}_{-1}$ ) and a lamp rheostat for IM loading is used. K-type thermocouples BK-50 (air probe - SE000) are used for temperature measuring of the IM stator frame and stator windings. All thermocouples are connected to a data logger Pico-Log TC-08 with built in cold junction compensation (accuracy of temperature reading $- \pm 0.2 \%$ of temperature value $\pm 0.5^{\circ} \mathrm{C}$ ). The IM frametemperature is measured inside the terminal box. The stator winding temperatures are measured in the end winding at the shaft (drive) side. For measuring of the IM stator current and voltage - the current sensor (current clamps 3XTA011AC), voltage leads and data logger Simple Logger II L562 (accuracy - current $\pm 0.5 \%$ of reading $+1 \mathrm{mV}$, voltage $- \pm 0.5 \%$ of reading $+1 \mathrm{~V}$ ) are used. Rotor rotation speed is measured with a LINE SEIKI tachometer TM-4010 (accuracy $\pm 0.01 \%$ \pm 1 digit). Experimental tests are performed under normal conditions at rated load till steady state is reached. Then air input channels in the fan cover are blocked to imitate impaired cooling. Least square regression is performed in $\mathrm{R}$ and stantard error $S$ is used to evaluate the fitted curve to the experimental results.

$R_{1}$ and $R_{2}$ are calculated using steady state temperature values $\theta_{s}, \theta_{f}$ and $\theta_{a} . C_{1}$ and $C_{2}$ is obtained from the thermal model using the experimental test results. Power losses in stator windings are calculated from the stator current and active resistance $R_{s}$. $R_{s}$ is corrected to stator winding temperature change. The complete scheme of the proposed stator winding temperature estimation method is shown in Figure 2. The simulation is done in Matlab Simulink environment.

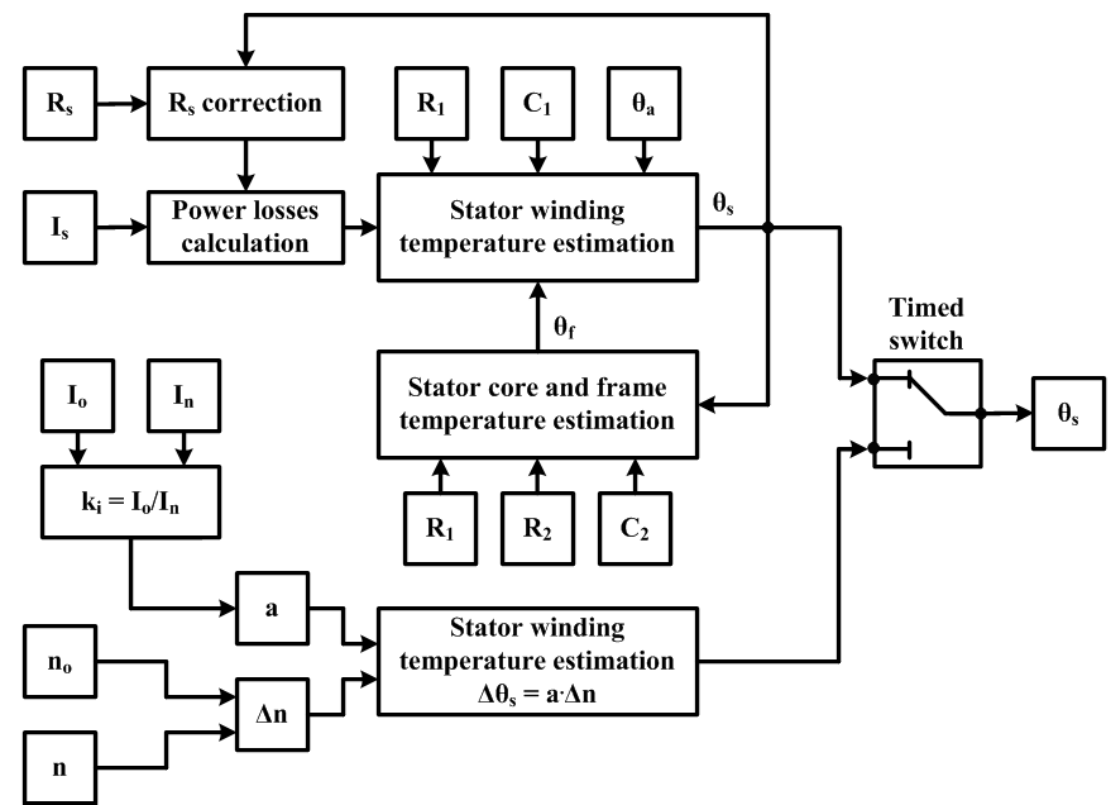

Fig. 2. Induction motor stator winding temperature estimation block diagram of proposed method 


\section{Results and discussion}

Experimental tests results of $1.1 \mathrm{~kW}$ under constant rated load show that during the transient thermal process the stator current and rotor speed decrease (Figure 3). The stator current and rotor speed changes till steady state can be described by the first order thermal model equation, thus the rotor speed decrease is due to the rotor winding temperature increase, while the stator current decrease due to $R_{s}$ and $R_{r}$ increase and rotor speed decrease (less work is done).

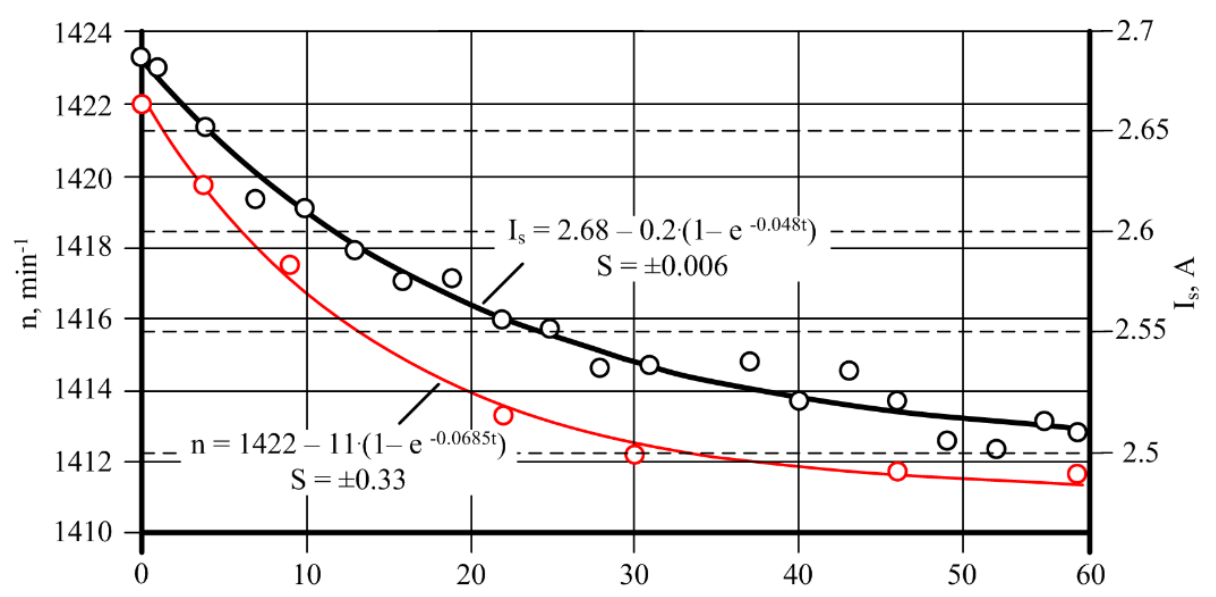

Fig. 3. Stator current and rotor speed changes during induction motor transient heating

Using the steady state test results and the thermal model the following parameters are obtained: $R_{1}=0.45^{\circ} \mathrm{C}^{-1}, R_{2}=5.5^{\circ} \mathrm{C}^{-1}, C_{1}=900 \mathrm{~J}^{\circ} \mathrm{C}^{-1}, C_{2}=2400 \mathrm{~J}^{\circ} \mathrm{C}^{-1}$. Correlation between the stator winding temperature and rotor speed changes is show in Figure 4. The correlation is almost linear, apart from the short period after the motor start, and the coefficient $a=3.66{ }^{\circ} \mathrm{C} \cdot \mathrm{min}^{-1}$ obtained from the linear regression equation.

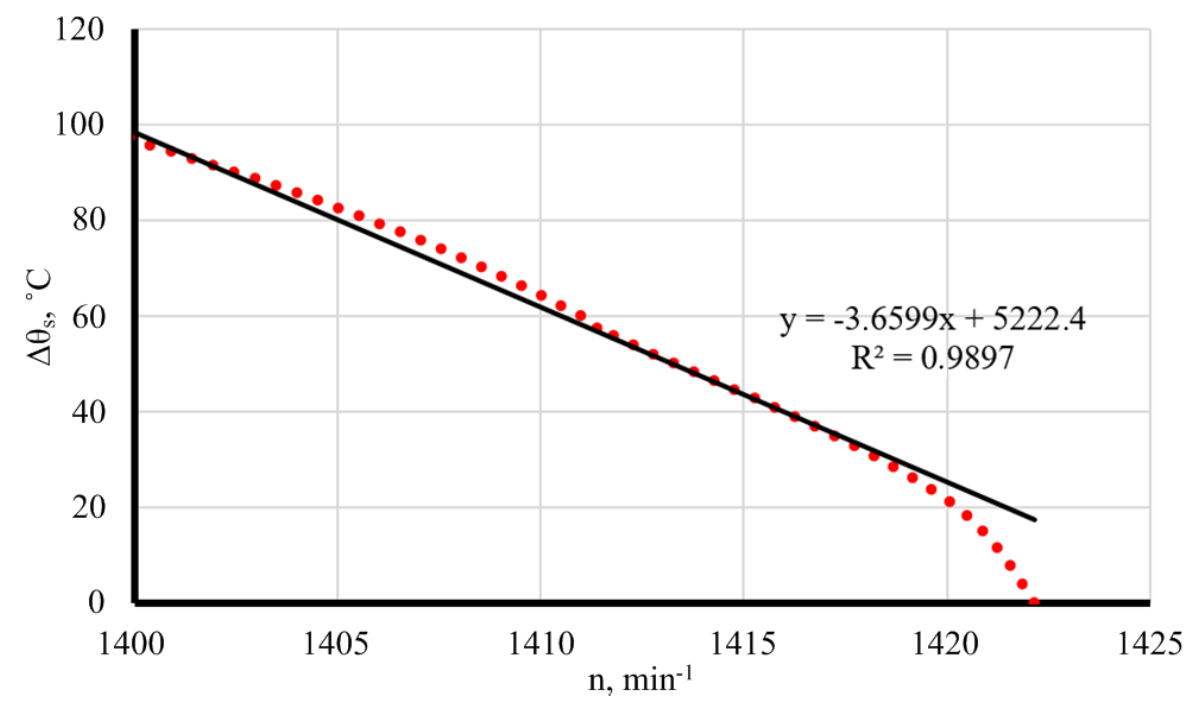

Fig. 4. Stator winding and rotor speed changes correlation during induction motor transient heating at rated load

After obtaining all needed parameters the stator winding temperature is estimated using the thermal model and rotor speed equation 2 in Matlab Simulink and the results are presented in Figure 5. As we can see, using only equation 2 to simulate the stator winding temperature during the first 10 minutes produces a significant error. This is why for the first 8 minutes, this time is obtained from the test and simulation results, the thermal model is used. Then a timed switch is used to switch from the thermal model to stator temperature estimation from the rotor speed. The root square error between the test and simulation results is with $1.5^{\circ} \mathrm{C}$ during the first 57 minutes (Figure 6). After that the ventilation air flow is blocked, heat dissipation decreased and the motors starts to heat again. Due to different stator and rotor thermal inertias, the error increases to maximum of $4{ }^{\circ} \mathrm{C}$ and then decreases. 
The difference between the test and simulation results is $2{ }^{\circ} \mathrm{C}$ at stator winding temperature $130{ }^{\circ} \mathrm{C}$, which is insulation class B thermal limit.

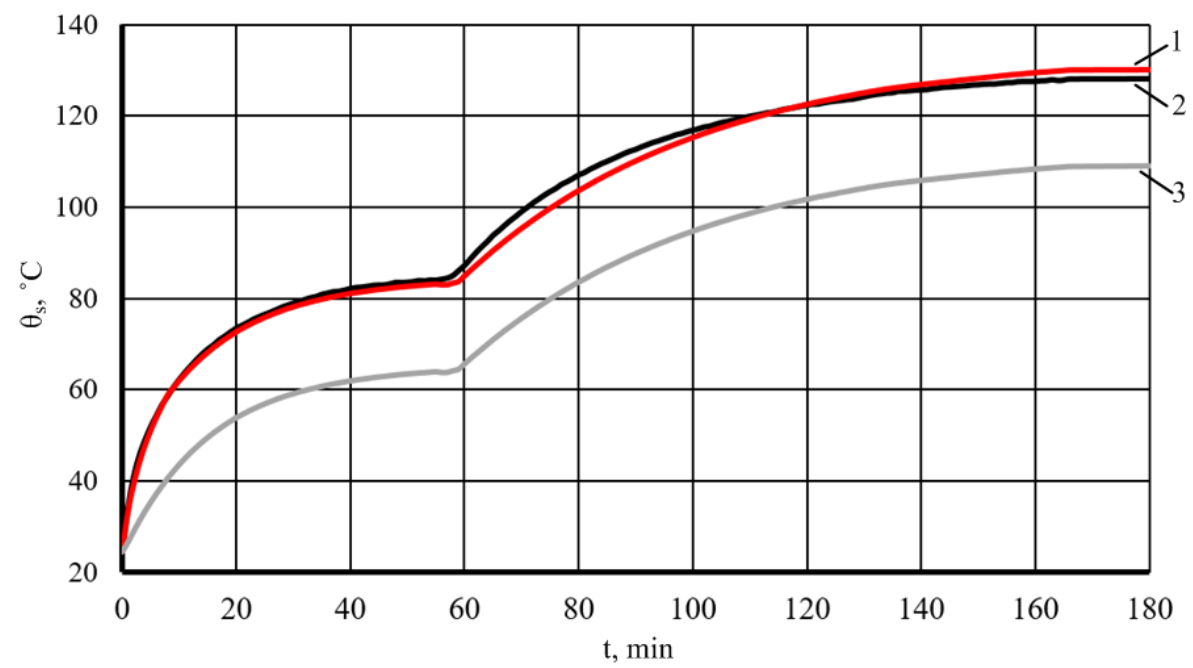

Fig. 5. Stator winding temperature simulation results: 1 - simulation results with combined method; 2 - experimental results; 3 - simulation results using only rotor speed

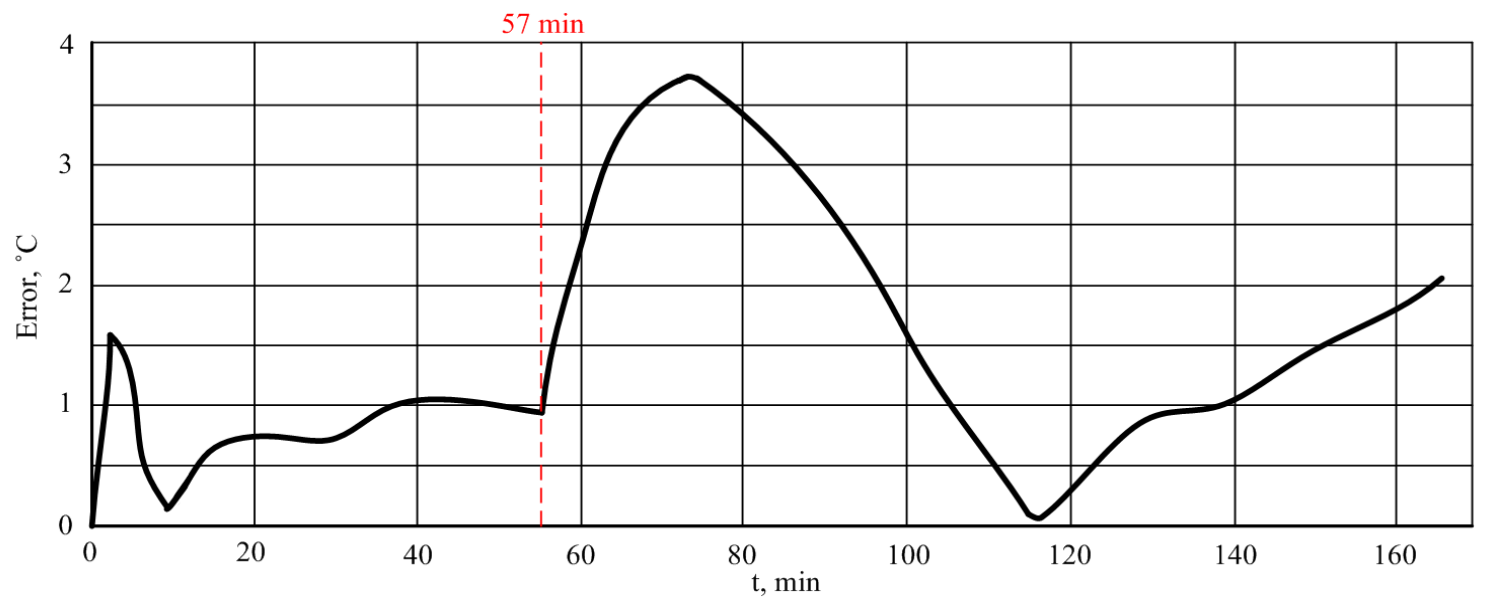

Fig. 6. Error between simulation and test results

Simulation results show that the proposed stator winding temperature estimation method has an adequate accuracy. This method requires only stator current and rotor speed measurements. Rotor speed can be estimated from the stator current harmonics as shown in [16]. Knowing the motor thermal parameters and coefficient $a$ values at different loads, only the stator current measurement is required. This makes the proposed method possible to be used as a simple and economically effective protection solution for small power S1 duty cycle induction motors.

\section{Conclusions}

1. Experimental results show that during heating the transient process of the induction motor stator current and rotor speed decreases due to heating of the IM stator and rotor windings. After short delay, caused by different thermal inertia between the rotor and stator windings, correlation between the stator winding temperature and rotor speed changes is linear at rated load.

2. Simulation results show that the difference between the simulation and test results is $2{ }^{\circ} \mathrm{C}$. A sudden impaired cooling condition or significant ambient temperature change will cause a higher error $4{ }^{\circ} \mathrm{C}$ due to thermal inertia, but the error will decrease before the stator winding temperature reaches insulation class thermal limit. This makes the proposed stator temperature estimation method capable to monitor the stator winding temperature under impaired cooling and/or high ambient temperature conditions with adequate accuracy. 
3. With known induction motor thermal parameters the proposed method can use only stator current measurements to estimate the stator winding temperature. It makes this method to be potentially cost effective for small power induction motors with S1 duty cycle.

\section{References}

[1] Bertoldi P. Recent development in energy efficiency policy in the EU, Proc. OF Energy Efficiency in Motor Drive Systems (EEMODS'15), Helsinki, Finland, Spetember 15-17, 2015.

[2] Thorsen O.V., Dalva M. A Survey of faults on induction motors in offshore oil industry, petrochemical industry, gas terminals and oil refineries. IEEE Transactions of Industry Applications, Vol. 31, No. 5, 1995, pp. 1186-1196.

[3] Bonnett A.H. Root cause failure analysis for AC induction motors in the petroleum and chemical industry. In: The 57th annual Petroleum and Chemical Industry Conference. 2010, IEEE, San Antonio, USA, pp. 1-13.

[4] Sniders A., 1995. Reliability and protection of induction motors during overload regimes. BalticElectrical Engineering Review 2, pp. 25-28.

[5] Хомутов С. Система повышения надежности электродвигателей в сельском хозяйстве на основе комплексной диагностики и эффективной технологии восстановления изоляции (Induction motor reliability improvement system in agriculture based on complex diagnostics and effective insulation restoring technology). Dissertation. Barnaul, 2010, 526 p. (In Russian).

[6] Venkataraman B., Godsey B., Premerlani W., Shulman E., Thakur M., Midence R. Fundamentals of a motor thermal model and its applications in motor protection. In: The58th annual conference "Protective Relay Engineers". 2005, Black \& Veatch Corporation, Kansas City, USA, pp. 127-144.

[7] Шипалов В. Эксплуатационная эффективность электропривода вентиляторов в птичниках с индукционным регулятором напряжения (Operation efficiency of fan electric drive with induction voltage regulator in hen houses). Dissertation. Krasnodar, 2009, 142 p. (In Russian).

[8] Gedzurs A. Operation reliability of induction motors at egg processing plant 'Balticovo'. Agronomy Research 2016, Vol.14, Special Issue 1, pp. 1161-1168.

[9] Abou-El-Ela M.S., Megahed A. I. Malik O. P.Thermal model based digital relaying algorithm for induction motor protection. Proceedings of 1996 Canadian Conference on Electrical and Computer Engineering. 1996, Calgary, Alta, vol. 2, pp. 1016-1019.

[10] DuYi., Habetler T. G., Gordon Harley R. Methods for thermal protection of medium voltage induction motors - A review. 2008 International Conference on Condition Monitoring and Diagnosis, 2008, Beijing, pp. 229-233.

[11] Hurst K. D.,HabetlerT. G. A thermal monitoring and parameter tuning scheme for induction machines. Industry Applications Conference, 1997, vol. 1, pp. 136-142.

[12] BeguenaneR., BenbouzidM. E. H.Induction motors thermal monitoring by means of rotor resistance identification. Energy Conversion IEEE Transaction, 1999, vol. 14 pp. 566-570.

[13] WlasM., Krzeminski Z.,Toliyat H. A. Neural-Network-Based Parameter Estimations of Induction Motors.In IEEE Transactions on IndustrialElectronics,April 2008, vol. 55, no. 4, pp. 1783-1794.

[14] Sang-Bin Lee,HabetlerT. G. A remote and sensorless thermal protection scheme for small lineconnected ac machines.Industry Applications IEEE Transactions, 2003, vol. 39 pp. 1323-1332.

[15]Zhang P., LuB.,HabetlerT. G. A Nonintrusive Induction Motor Stator Resistance Estimation Method using a Soft-Starter. Diagnostics for Electric Machines Power Electronics and Drives 2007. SDEMPED 2007. IEEE International Symposium, pp. 197-202.

[16] Gao Z. Sensorless stator winding temperature estimation for induction machines. Dissertation. Georgia Institute of Technology, 2006, $185 \mathrm{p}$.

[17] KubotaH.,Matsuse K., Nakano T. DSP-based speed adaptive flux observer of induction motor. IEEE Trans. Industry Applications, vol. 29 no. 2, 1993, pp. 344-348.

[18] Gedzurs A. Heating of low-power induction motor under no-load mode and different cooling conditions. Research for rural development 2014: annual 20th international scientific conference proceedings, Latvia University of Agriculture. Jelgava: LLU, 2014. Vol.1, pp. 219.-224. 